\title{
Quantitation of Human Gamma Globin Genes and Gamma Globin mRNA with Purified Gamma
}

\section{Globin Complementary DNA}

\author{
Francesco Ramirez, Joyce V. O’Donnell, Clayton Natta, and Arthur Bank \\ From the Department of Human Genetics and Development, Medicine and Pathology, Columbia \\ University, College of Physicians and Surgeons, New York 10032
}

A B S T R A C T Complementary DNA (cDNA) specific for $\gamma$-globin nucleotide sequences has been prepared by hybridizing total cDNA made from cord blood messenger RNA (mRNA) as template to an excess of normal adult human globin mRNA and recovering the single-stranded cDNA from hydroxylapatite. The specificity of the $\gamma$ cDNA for $\gamma$ mRNA sequences is strongly supported by the hybridization of this cDNA at low $C_{o} t$ values $\left(C_{o}\right.$, concentration of RNA and $t$, time in seconds) to RNA samples containing large amounts of functional $\gamma$ globin mRNA and the lack of hybridization to RNA samples containing little, if any, $\gamma$-globin mRNA. The absence of cross-hybridization of $\gamma$ cDNA with $\alpha, \beta$, and $\delta$ mRNAs is demonstrated by the complete hybridization of the $\gamma$ cDNA to mRNA samples completely lacking either $\alpha$ or $\beta$ and $\delta$ mRNA. An estimate of the number of $\gamma$-globin genes in human cellular DNA was obtained by hybridization of purified $\gamma$ cDNA to DNA from spleen and white blood cells of normal and $\beta$-thalassemia subjects and measurement of the percent of $\gamma$ cDNA hybridized at saturation. The results indicate that there are between one and two $\gamma$-globin genes per total haploid gene DNA equivalent obtained from both normal and $\beta$-thalassemia subjects. These values are consistent with genetic evidence for the presence of multiple $\gamma$ gene loci in human cells. The finding that the number of $\gamma$-globin genes in $\beta$-thalassemia DNA is similar to that in nonthalassemia DNA indicates that a deletion of $\gamma$-globin genes cannot account for either

A portion of this work appeared in the Abstracts of the 18th Annual Meeting of the American Society of Hematology, Dallas, Tex., December 1975.

Dr. Bank is a Faculty Research Scholar of the American Cancer Society. Dr. Ramirez is a Visiting Fellow from the Instituto di Anatomia Comparata, Palermo, Italy.

Received for publication $15 \mathrm{July} 1976$ and in revised form 23 August 1976. the inadequate $\gamma$-globin synthesis or indirectly for the decreased or absent $\beta$-globin synthesis in $\beta$-thalassemia cells.

\section{INTRODUCTION}

The use of highly radioactive complementary DNA (cDNA $)^{1}$ has recently permitted the measurement of the number of globin genes in a variety of mammalian species (1-3). In addition, purified $\alpha$ and $\beta$ cDNAs from human cells have been used to quantitate the relative number of $\alpha$ - and $\beta$-globin genes in human DNA $(4,5)$. The results indicate that there are between one and four $\alpha$-globin genes, and one and five $\beta$-globin genes per haploid human genome. More recently, the specificity of the hybridization of purified $\alpha$ and $\beta$ cDNA probes to complementary nucleotide sequences in human cellular DNA has been strengthened by the detection of deletions of $\alpha$ - and $\beta$-like globin genes in certain forms of $\alpha$ - and $\beta$-thalassemia $(4,6-8)$ and in hereditary persistance of fetal hemoglobin (8-10). To quantitate the number of $\gamma$-globin genes in human cells, we have prepared specific $\gamma$-globin cDNA by hybridizing the cDNA synthesized with cord blood messenger RNA (mRNA) as substrate $(\alpha, \beta$, and $\gamma$ mRNA) to an excess of normal adult reticulocyte mRNA containing only $\alpha$ and $\beta$ mRNA. After $\alpha$ and $\beta$ cDNA were allowed to become hybridized, the cDNA remaining single stranded was isolated. This single-stranded material specifically hybridizes with mRNA from cells known to contain large amounts of $\gamma$ mRNA, whether of adult or fetal origin, while there is a lack of hybridization of this $\gamma$ cDNA when hybridized to mRNAs containing small amounts of $\gamma$ mRNA.

\footnotetext{
${ }^{1}$ Abbreviations used in this paper: $C_{o}$, concentration of RNA; cDNA, complementary DNA; mRNA, messenger RNA; $t$, time in seconds.
} 


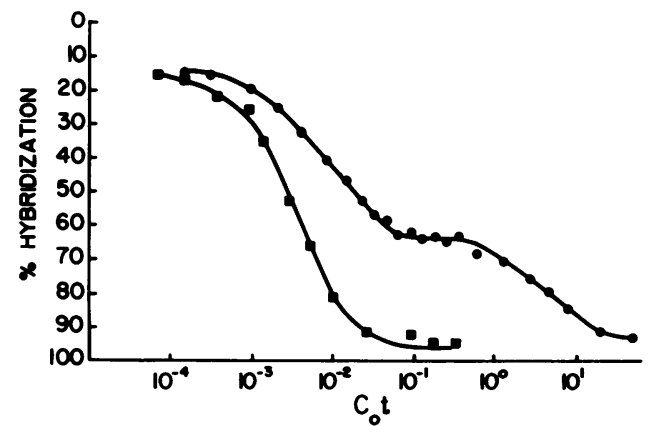

FIGURE 1 Hybridization of mRNA from cord blood and normal adult reticulocytes to cord blood cDNA: $32 \mathrm{pg}-20 \mu \mathrm{g}$ of cord blood mRNA was annealed to $2,000 \mathrm{cpm}(0.143 \mathrm{ng})$ of cord blood cDNA for $4 \mathrm{~h}$ at $68^{\circ} \mathrm{C}$ to obtain the $C_{o} t$ values indicated. The percentage of hybridization of cDNA was assayed as described in Methods ( $\square-\square) .32 \mathrm{pg}-0.2 \mu \mathrm{g}$ of normal adult reticulocyte mRNA was annealed to $2,000 \mathrm{cpm}$ (0.143 ng) of cord blood cDNA as described above (O-O).

With this highly specific $\gamma$ cDNA, the relative amounts of $\gamma$-globin gene material in DNA from spleens and peripheral blood cells of patients with nonthalassemic conditions and with $\beta$-thalassemia have been compared. Calculation of the number of $\gamma$-globin genes indicate that there are between one and two $\gamma$-globin genes per total haploid gene DNA equivalent. There is no evidence for deletion of $\gamma$-globin gene material in $\beta$-thalassemia which could account for the inadequate compensation by $\gamma$-globin synthesis for the decrease or absence of $\beta$-globin in these cells. In addition, there is no evidence that $\gamma$ gene deletion is indirectly responsible for the relative decrease in $\beta$-globin mRNA production in $\beta^{+}$-thalassemia.

\section{METHODS}

Human globin mRNAs were obtained by extraction of either peripheral blood or liver of a patient with hydrops fetalis as described previously (4). The 6-16S RNA region was routinely isolated for use in the preparation of globin cDNA and for hybridization to purified and total cDNA. $\alpha$ and $\beta$ cDNA were purified as previously reported (4). Globin synthesis in intact cells and translation of globin mRNA in a Krebs ascites tumor cell-free system was as previously described (11).

Preparation of $\gamma$-globin cDNA. The preparation of $\gamma$ globin cDNA was analogous to that described previously (12). In our experiments, $10 \mu \mathrm{g}$ of cord blood mRNA was used as template for the production of $\alpha^{-}, \beta-$, and $\gamma$-globin cDNAs. $4 \times 10^{6} \mathrm{cpm}$ of this cord blood cDNA with a calculated specific activity of approximately $14,000 \mathrm{cpm} / \mathrm{ng}(3)$ was then hybridized to $5 \mu \mathrm{g}$ of globin mRNA ( $\alpha$ and $\beta$ ) prepared from the reticulocytes of an adult patient with a hemolytic anemia. After $4 \mathrm{~h}$ of hybridization equivalent to a $C_{o} t$ ( $C_{o}$, concentration of RNA times $t$, time in seconds) of 0.25 , the hybridized and unhybridized cDNA and mRNA species were separated on hydroxylapatite. The singlestranded material was eluted with $0.12 \mathrm{M}$ sodium phosphate in $\mathbf{0 . 4 \%}$ sodium dodecyl sulfate, while the double-stranded material was eluted with $0.4 \mathrm{M}$ phosphate in $0.4 \%$ sodium dodecyl sulfate. The hydroxylapatite eluates were passed through a column of Sephadex G-50 (Pharmacia Laboratories, Inc., Piscataway, N.J.) and the excluded volume was collected. The material was then treated with alkali for $18 \mathrm{~h}$ at $37^{\circ} \mathrm{C}$. The cDNA eluted initially as the double strand was used for subsequent purification of $\alpha$ - and $\beta$-globin cDNA (4), while the single-stranded material was used as $\gamma$-globin cDNA. The $\gamma$ cDNA migrated as a single homogeneous peak of 7S DNA on alkaline sucrose gradients (13) and contained approximately 500 nucleotides when analyzed by polyacrylamide gel electrophoresis in formamide (14).

Preparation of human DNA. DNA was prepared from human spleen and liver of patients with and without $\beta$-thalassemia, as described previously $(3,4)$. DNA from peripheral blood was prepared similarly, except that the blood sample containing white blood cells was washed three times with $10 \mathrm{vol}$ of isotonic saline, frozen, and thawed before washing with $5 \%$ sucrose containing $1 \mathrm{mM} \mathrm{MgCl}_{2}$, $1 \mathrm{mM}$ sodium phosphate ( $\mathrm{pH} 6.5$ ), $0.4 \%$ deoxycholate, and 0.8\% Nonidet P40 (Shell International Ltd., London, England).

Hybridization of cDNA with human mRNA and cellular DNA. Globin cDNA was hybridized with mRNA under conditions described previously (15) and for $4 \mathrm{~h}$ unless otherwise specified. With this methodology, it has been shown previously (16) that the relative $C_{o} t \quad 1 / 2$ values obtained (Table I) are proportional to the amount of mRNA present over a wide range of RNA concentrations. Globin mRNA was prepared by isolating 6-16S RNA from sucrose density gradients unless otherwise indicated (13). Hybridization of globin cDNA with spleen, liver, or white cell DNA was also previously described $(4,5)$.

\section{RESULTS}

Properties of cord blood cDNA. The hybridization kinetics of total cord blood cDNA to cord blood mRNA and normal adult reticulocyte globin mRNA is shown in Fig. 1. When cord blood cDNA and cord blood mRNA are annealed, a monophasic hybridization curve is obtained, indicating that the relative proportions of the different nucleotide sequences $(\alpha, \beta$, and $\gamma$ ) are similar in both mRNA and cDNA. A similar monophasic curve is obtained when normal reticulocyte mRNA is hybridized with total cDNA prepared from normal adult reticulocyte mRNA (4). By contrast, when cord blood cDNA is annealed to normal reticulocyte mRNA containing predominantly $\alpha$ and $\beta$ mRNA, the hybridization curve is diphasic (Fig. 1). The initial hybridization to $65 \%$ is due to the re-annealing of $\alpha$ and $\beta$ complementary sequences. Only after an additional 50-100-fold excess of normal mRNA is added is the remaining cDNA hybridized. This is presumably due to the small amount of $\gamma$ mRNA present in normal reticulocyte mRNA, which requires that a large excess of this mRNA be added to hybridize the $\gamma$ cDNA of the cord blood cDNA. Presumed $\gamma$ cDNA was isolated from the total cord blood cDNA by separating hybridized and unhybridized cDNA at a $C_{o} t$ of 0.25 (Fig. 1) by hydroxylapatite chromatography. 


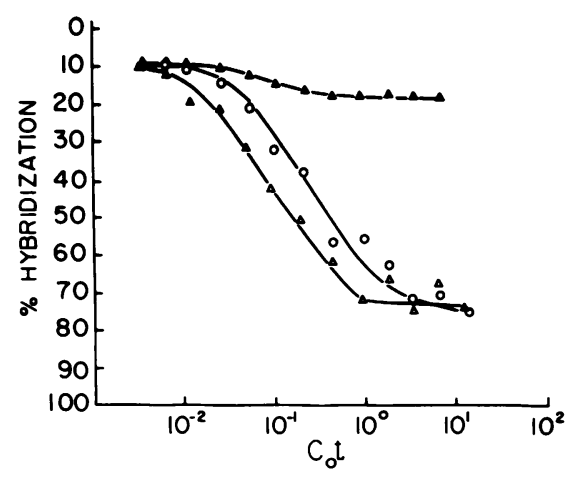

FIGURE 2 Hybridization of $\delta \beta$-thalassemia mRNA with $\alpha, \beta$, and $\gamma$ cDNA. $0.1 \mathrm{ng}-0.36 \mu \mathrm{g}$ of mRNA was hybridized to $2,000 \mathrm{cpm}(0.143 \mathrm{ng})$ of $\alpha, \beta$, or $\gamma$ cDNA. Hybridization was for $24 \mathrm{~h}$ at $68^{\circ} \mathrm{C}$ to obtain the indicated $C_{o} t$ values. The percentage of hybridization was assayed as described in Methods. $(\Delta-\Delta) \alpha$ cDNA; $(\Delta-\Delta), \beta$ cDNA; $(\mathrm{O}-\mathrm{O}), \gamma$ cDNA.

The unhybridized cDNA isolated from cord blood cDNA after hybridization with normal reticulocyte mRNA will subsequently be called $\gamma$ cDNA. To demonstrate the specificity of the $\gamma$ cDNA for $\gamma$ mRNA sequences, the hybridization of $\alpha, \beta$, and $\gamma \mathrm{cDNA}$ was measured in RNAs containing different amounts of functional $\gamma$ mRNA.

Hybridization of $\delta \beta$-thalassemia mRNA. Globin mRNA was isolated from the peripheral blood cells of a patient homozygous for $\delta \beta$-thalassemia. The peripheral blood of this patient contains only $\mathrm{HbF}$ and when the reticulocytes of this patient were incubated with $\left[{ }^{3} \mathrm{H}\right]$ leucine, only $\gamma$ - and $\alpha$-globin were synthesized, in a ratio of $0.62: 1$ (17). Cell-free translation of this mRNA led to only $\gamma$ - and $\alpha$-globin synthesis in a ratio of $0.33: 1$. With purified $\beta$ cDNA, only $10 \%$ hybridization above background is obtained, even at $C_{o} t$ values of $10^{2}$ (Fig. 2). By contrast, over $80 \%$ of the $\gamma$ cDNA is hybridized at a $C_{o} t$ value approximately double that at which $\alpha$ cDNA is hybridized. These results indicate that the $\gamma \mathrm{cDNA}$ does not hybridize with $\beta$ mRNA (since no $\beta$ mRNA is present) and contains more than $80 \%$ of an mRNA species present in reticulocytes in amounts comparable to $\alpha$ mRNA. These observations also show that the $\gamma \mathrm{cDNA}$ is not a "nonglobin" cDNA species present in cord blood, since it hybridizes at $C_{o} t$ values comparable to $\alpha$ cDNA with RNA from an adult patient known to have comparable amounts of $\alpha$ and $\gamma$ mRNA. In addition, when $\gamma$ cDNA is hybridized to either 6-16S RNA or total RNA isolated from human fibroblast cell lines, less than $10 \%$ of the $\gamma \mathrm{cDNA}$ is hybridized at $C_{o} t$ values of $10^{3}$.

Hybridization to hydrops fetalis mRNA. The possibility that the $\gamma$ cDNA cross-hybridizes to $\alpha$ mRNA sequences was studied by hybridization of the $\gamma \mathrm{cDNA}$

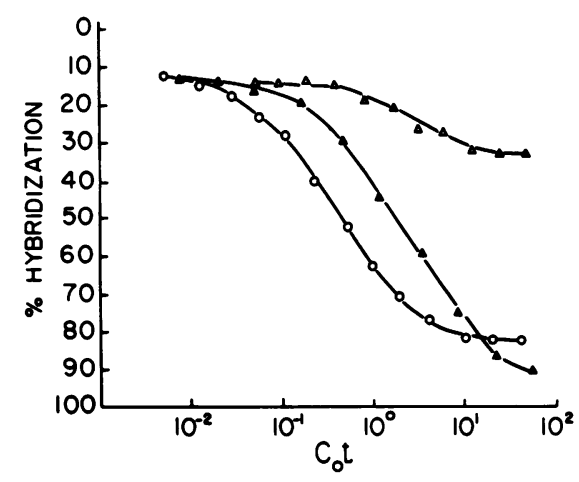

FIgure 3 Hybridization of mRNA from hydrops fetalis liver with $\beta$ and $\gamma$ cDNA. 32 ng-32 $\mu \mathrm{g}$ of mRNA was hybridized to $2,000 \mathrm{cpm}(0.143 \mathrm{ng})$ of $\gamma$ and $\beta \mathrm{cDNA}$, respectively. Hybridization was for $4 \mathrm{~h}$ at $68^{\circ} \mathrm{C}$ to obtain the indicated $C_{o} t$ values. The percentage of hybridization was assayed as described in Methods. $(\boldsymbol{\Delta}-\boldsymbol{\Delta}), \boldsymbol{\beta}$ cDNA; $(\mathrm{O}-\boldsymbol{O}), \gamma$ cDNA; $(\triangle \longrightarrow \triangle), \alpha$ cDNA.

to hydrops fetalis mRNA, which contains no $\alpha$ mRNA (4). When $\gamma$ and $\beta$ cDNA are hybridized to mRNA prepared from the liver of a patient with hydrops fetalis (Fig. 3), there is six times more $\gamma$ mRNA than $\beta$ mRNA based on the differences in $C_{o} t 1 / 2$ of mRNA required to protect similar amounts of each cDNA probe. These relative amounts of $\gamma$ and $\beta$ mRNA are consistent with the 5-10-fold greater $\gamma$ as compared to $\beta$-globin present and synthesized in hydrops fetalis cells (Table I, ref. 4). The $\alpha$ cDNA hybridizes to $20 \%$ above background even at high $C_{o} t$ values (Fig. 3, ref. 4). The hybridization results with $\gamma$ and $\beta$ probes indicate that the $\gamma \mathrm{cDNA}$ hybridizes to $\gamma$ mRNA at a rate independent of the amount of $\beta$ mRNA present, and conversely, that $\beta$ cDNA hybridizes to $\beta$ mRNA at a rate independent of the amount of $\gamma$ mRNA present.

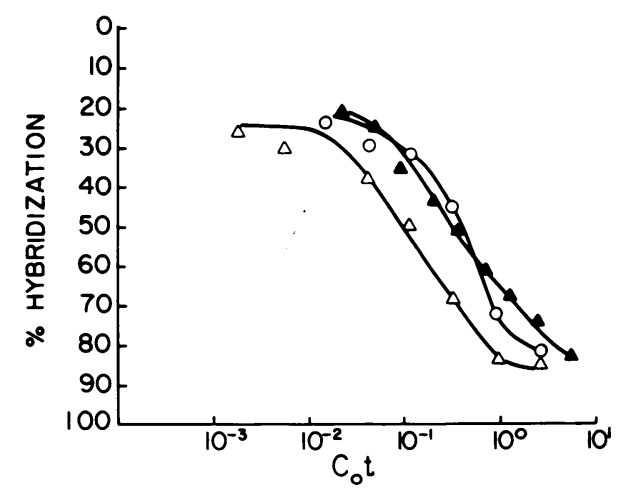

FIGURE 4 Hybridization of mRNA from reticulocytes of a homozygous $\beta$-thalassemia patient with $\alpha, \beta$, and $\gamma$ cDNA. $0.8 \mathrm{ng}-0.28 \mu \mathrm{g}$ of mRNA was hybridized to $2,000 \mathrm{cpm}$ $\left(0.143 \mathrm{ng}\right.$ ) of $\alpha, \beta$, or $\gamma \mathrm{cDNA}$. Hybridization was for $4 \mathrm{~h}$ at $68^{\circ} \mathrm{C}$ to obtain the indicated $C_{o} t$ values. The percentage of hybridization was assayed as described in Methods. $(\triangle \longrightarrow \Delta)$, $\alpha$ cDNA; $(\boldsymbol{\Delta}-\mathbf{\Delta}), \beta$ cDNA; $(\bigcirc-O), \gamma$ cDNA. 
TABLE I

Relative Globin mRNA Content and Globin Synthesis in Human Erythroid Cells

\begin{tabular}{|c|c|c|c|c|c|c|}
\hline \multirow[b]{2}{*}{ Source } & \multicolumn{3}{|c|}{ mRNA content* } & \multicolumn{3}{|c|}{ Globin synthesis } \\
\hline & $\alpha$ & $\beta$ & $\gamma$ & $\alpha$ & $\beta$ & $\gamma$ \\
\hline Normal-1 (Fig. $5 b)$ & 1.0 & 1.0 & 0.01 & 1.0 & 1.0 & 0.01 \\
\hline Normal-2 & 1.0 & 1.1 & 0.005 & 1.0 & 1.0 & 0.01 \\
\hline Normal-3 & 1.0 & 1.0 & 0.003 & - & - & - \\
\hline Normal-4 & 1.0 & 1.0 & 0.025 & - & - & - \\
\hline Homozygous $\delta \beta$-thal (Fig. 2) & 1.0 & - & 0.33 & 1.0 & - & 0.62 \\
\hline Hydrops fetalis (Fig. 3) & - & 1.0 & 5.9 & - & 1.0 & 6.0 \\
\hline Cord blood (Fig. $5 a$ ) & 1.0 & 1.0 & 1.8 & 1.0 & 0.4 & 0.6 \\
\hline Homozygous $\beta^{+}$thal (Fig. 4) & 1.0 & 0.072 & 0.08 & 1.0 & 0.27 & 0.27 \\
\hline Homozygous $\beta^{+}$thal & 1.0 & 0.25 & 0.25 & 1.0 & 0.23 & 0.21 \\
\hline $\mathrm{HbH}-1$ & 1.0 & 3.3 & 0.01 & 1.0 & 1.8 & 0.01 \\
\hline $\mathrm{HbH}$ (bone marrow) -1 & 1.0 & 3.8 & 0.004 & 1.0 & 1.8 & 0.01 \\
\hline
\end{tabular}

* The relative mRNA content is calculated from the $C_{0} t 1 / 2$ values obtained by hybridization to $\alpha, \beta$, and $\gamma$ cDNAs. The relative mRNA content is the reciprocal of the $C_{0} t 1 / 2 \mathrm{~s}$; for example, $\alpha / \beta$ mRNA content $=C_{0} t^{1 / 2} \beta / C_{0} t 1 / 2 \alpha$. The results have been normalized compared to an $\alpha$ mRNA value of 1.0, except for hydrops fetalis mRNA, for which the value for $\beta \mathrm{mRNA}$ is set as 1.0 .

$\ddagger$ Globin synthesis in intact cells with $\left[{ }^{3} \mathrm{H}\right]$ leucine as described in the text $\alpha$-globin synthesis has been set at 1.0, except for hydrops fetalis, for which $\beta$-globin synthesis is set 1.0 .

Over $90 \%$ of the $\gamma$ cDNA hybridizes at a low $C_{o} t$, indicating that over $90 \%$ of the $\gamma \mathrm{cDNA}$ is not $\alpha \mathrm{cDNA}$.

Hybridization to $\alpha$ and $\beta$ thalassemia mRNA. When mRNA isolated from reticulocytes of two patients with homozygous $\beta^{+}$thalassemia is hybridized with $\alpha, \beta$, and $\gamma$ cDNAs, the results indicate that there is a significant amount of $\gamma$ mRNA present, 0.08 and 0.25 times as much $\gamma$ mRNA as $\alpha$ mRNA (Fig. 4, Table I). In these experiments, it is also clear that the amount of $\gamma \mathrm{cDNA}$ present in the cells measured by comparing hybridization to $\alpha, \beta$, and $\gamma$ cDNA is comparable to the relative amounts of $\gamma-, \beta$-, and $\alpha$-globin synthesized by these cells or by mRNA isolated from them and translated in cell-free systems. In addition, with the mRNA of five patients with $\beta^{0}$-thalassemia from Ferrara described elsewhere (8), the ratio of $\gamma$ to $\alpha$ mRNA obtained by hybridization was 0.23 to 0.77 , comparable to the relative amounts of $\gamma$ - and $\alpha$-globin present in intact cells. When the mRNA from a patient with hemoglobin $\mathrm{H}$ disease $(\mathrm{HbH})$, a form of $\alpha$-thalassemia, is hybridized to $\alpha, \beta$, and $\gamma \mathrm{cDNA}$, there is a threefold excess of $\beta$ mRNA over $\alpha$ mRNA, and very little $\gamma$ mRNA (Table I). Again, there is no evidence for hybridization of $\gamma$ cDNA to the $\beta$ mRNA present in this case. These results are consistent with the negligible $\gamma$-globin synthesis in $\mathrm{HbH}$ cells.

Hybridization to normal and cord blood mRNA. Globin mRNA from reticulocytes of fetuses at birth (cord blood) was hybridized to purified $\alpha, \beta$, and $\gamma$ cDNAs (Table I, Fig. $5 a$ ). When cord blood mRNA is hybridized to $\alpha, \beta$, and $\gamma$ cDNA, the $C_{o} t 1 / 2$ with $\alpha, \beta$, and $\gamma$ mRNA are similar (Fig. 5a, Table I), indicating that approximately equal amounts of these RNAs are present in the cord blood mRNA. These results are consistent with the relatively equal synthesis of $\alpha$-, $\beta$-, and $\gamma$-globin in intact cells of cord blood and by isolated mRNA in cell-free systems (Table I). When $\gamma$ cDNA is annealed with normal adult reticulocyte mRNA, there is slow gradual rate of hybridization of the $\gamma \mathrm{cDNA}$ until a $C_{o} t$ of $10^{-2}$, and more rapid hybridization at $C_{o} t$ values above $10^{-2}$, until the probe is fully hybridized at $C_{0} t$ values $50-100$ times that required to hybridize $\alpha$ or $\beta$ cDNA (Fig. 5b). The hybridization of $\gamma$ cDNA with normal mRNA at low $C_{o} t$ values (less than 0.01 ) is probably due to contamination of the $\gamma$-globin cDNA with $\alpha$ or $\beta$ cDNA. This level of contamination of $\gamma$ cDNA by $\alpha$ and $\beta$ cDNA (about $20 \%$ ) is consistent with that obtained with $\delta \beta$-thalassemia and hydrops fetalis mRNA.
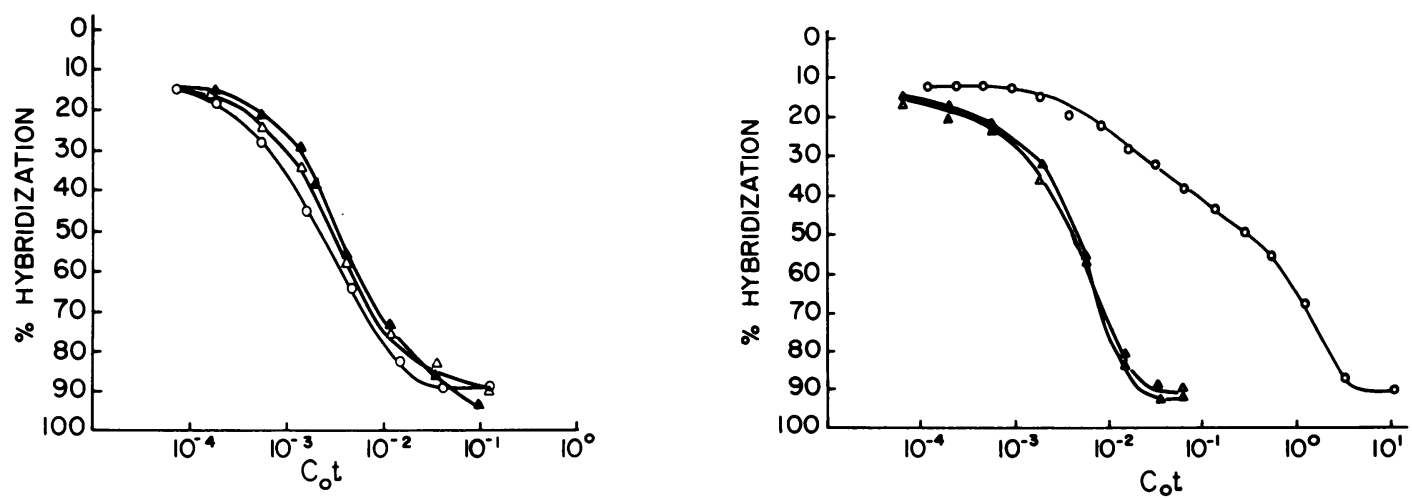

FIGURE 5 (a) Hybridization of mRNA from cord blood with $\alpha, \beta$, and $\gamma$ cDNA. 36 pg-48 ng of mRNA was hybridized to $2,000 \mathrm{cpm}(0.143 \mathrm{ng})$ of $\alpha, \beta$, or $\gamma \mathrm{cDNA}$ for $4 \mathrm{~h}$ at $68^{\circ} \mathrm{C}$ to obtain the indicated $C_{o} t$. The percentage of hybridization was assayed as described in Methods. $(\triangle \longrightarrow \triangle)$, $\alpha$ cDNA; $(\boldsymbol{\Delta}-\boldsymbol{\Delta}), \beta$ cDNA; $(O-O), \gamma$ cDNA. (b) Hybridization of mRNA from normal adult reticulocytes with $\alpha, \beta$ and $\gamma \mathrm{cDNA}$ : $32 \mathrm{pg}-4 \mu \mathrm{g}$ of normal adult reticulocyte mRNA was hybridized to $2,000 \mathrm{cpm}(0.143 \mathrm{ng})$ of purified $\alpha, \beta$, and $\gamma \mathrm{cDNA}$ for $4 \mathrm{~h}$ at $68^{\circ} \mathrm{C}$ to obtain the $C_{o} t$ values indicated. $(a)$, left; $(b)$, right. 


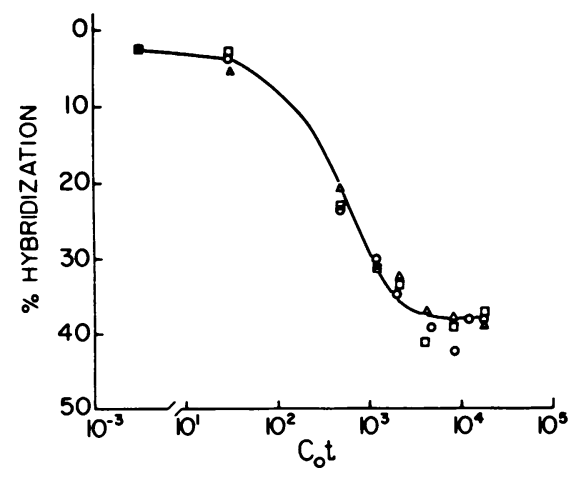

FIgURE 6 Hybridization of normal and thalassemia cellular spleen DNA to $\gamma \mathrm{cDNA}$. 45- $\mu$ l aliquots of a $300-\mu$ l incubation mixture containing $0.9 \mathrm{mg}$ of DNA and $4,200 \mathrm{cpm}(0.3 \mathrm{ng})$ of $\gamma \mathrm{cDNA}$ in $0.12 \mathrm{M}$ sodium phosphate $(\mathrm{pH} 6.8), 0.3 \mathrm{M} \mathrm{NaCl}$, $1 \mathrm{mM}$ EDTA, and $0.4 \%$ sodium dodecyl sulfate were heated in a boiling water bath for $15 \mathrm{~min}$ and incubated at $68^{\circ} \mathrm{C}$ for various times to attain the $C_{o} t$ values shown. The samples were assayed by hydroxylapatite as described previously (3). $(\mathrm{O}-\mathrm{O})$, normal spleen DNA; $(\triangle-\triangle), \boldsymbol{\beta}^{0}$-thalassemia spleen DNA; ( $\square-\square), \beta^{+}$-thalassemia spleen DNA.

Number of $\gamma$-globin genes in human DNA. We have previously reported that the relative numbers of $\alpha$ and $\beta$-globin genes in normal DNA (4). In these hybridizations with relative cDNA excess (see Table II, legend), a competition between the cDNA and one of the cellular DNA strands for the complementary cellular DNA strand limits the extent of cDNA hybridization (Fig. 6, Table II) (3). By contrast, in vast cellular DNA excess, over $80 \%$ of the $\gamma$ cDNA is hybridized. At inputs of cDNA per cellular DNA of $3.3 \times 10^{-7}$ (relative cDNA excess), the hybridization of normal and thalassemia DNA to $\gamma \mathrm{cDNA}$ was measured (Fig. 6, Table II). At saturation hybridization with these inputs, approximately $40 \%$ of the $\gamma \mathrm{cDNA}$ was hybridized. When DNA from patients with $\beta$-thalassemia is hybridized to $\gamma \mathrm{cDNA}$, results similar to those with DNA from normal cells are obtained (Fig. 6 , Table II). The $C_{o} t \quad 1 / 2$ of the unique sequences in unlabelled cellular DNA in these studies is approximately 1,100 , while that of the $\gamma$ cDNA was between 350 and 450 (Fig. 6). These data indicate no detectable deletion of $\gamma$-globin genes in $\beta$-thalassemia of either the $\beta^{+}$or $\beta^{0}$ type in the patients studied.

\section{DISCUSSION}

We have previously separated $\alpha$ and $\beta$ cDNA from total normal adult human cDNA by using mRNA from patients with hydrops fetalis that completely lacks $\alpha$ mRNA sequences. More recently, we have separated $\alpha$ and $\beta$ mRNAs by acrylamide gel electrophoresis and have prepared $\alpha$ and $\beta$ cDNA using these mRNAs. ${ }^{2}$

\footnotetext{
${ }^{2}$ Nudel, U., F. Ramirez, and A. Bank. In preparation.
}

The hybridization kinetics of the $\alpha$ and $\beta$ cDNA prepared by hybridization to hydrops fetalis mRNA and by electrophoresis are comparable. In the present study, a similar procedure has been used to isolate $\gamma$ cDNA from cord blood by hybridizing total cord cDNA to normal adult reticulocyte mRNA containing negligible amounts of $\gamma$ mRNA. The single-stranded cDNA recovered has been used as purified $\gamma$ cDNA. The specificity of the $\gamma \mathrm{cDNA}$ has been demonstrated by its complete hybridization at relatively low $C_{o} t$ values to a variety of mRNAs obtained from both adult and fetal cells known to contain large amounts of functional $\gamma$ mRNA. The complete hybridization of the $\gamma$ cDNA to mRNA from a patient homozygous for $\delta \beta$-thalassemia and completely lacking functional or structurally intact $\delta$ and $\beta$ mRNA indicates less than $20 \%$ contamination of $\gamma$ cDNA with $\delta$ or $\beta$ mRNA. In addition, the relatively similar $C_{o} t$ values at which $\gamma$ and $\alpha$ cDNAs are hybridized with $\delta \beta$ mRNA, and its lack of hybridization to fibroblast RNA make it extremely unlikely that the $\gamma$ cDNA is due to "nonglobin cDNA" resulting from nonglobin mRNA in the cord blood mRNA used to prepare the $\gamma \mathrm{cDNA}$. If the

TABLE II

Hybridization of $\gamma$-Globin cDNA with Human Cellular DNA

\begin{tabular}{ll}
\hline \multicolumn{1}{c}{ Source } & $\begin{array}{c}\gamma^{*} \\
\text { Hybrid } \\
\text { (gene no.)t }\end{array}$ \\
\hline Normal spleen-1 (Fig. 6) & $\%$ \\
Normal spleen-2 & $39(2)$ \\
Peripheral blood-1 & $36(1-2)$ \\
$\beta^{0}$ thalassemia spleen-1 (Fig. 6) & $35(1-2)$ \\
$\beta^{0}$ thalassemia spleen-1 & $40(2)$ \\
$\beta^{0}$ thalassemia peripheral blood-2 & $38(2)$ \\
$\beta^{+}$thalassemia spleen-1 (Fig. 6) & $31(1-2)$ \\
$\beta^{+}$thalassemia spleen-2 & $39(2)$ \\
$\beta^{+}$thalassemia spleen-3 & $36(1-2)$ \\
\hline
\end{tabular}

* Each hybridization contained $3.3 \times 10^{-7}$ as much cDNA as cellular DNA (see legend to Fig. 6 for typical inputs). The percent hybrid is the average of the values obtained at the plateau of hybridization at $C_{0} t$ values of 8,600 or greater. At least two determinations at different $C_{o} t$ values have been used in each experiment and in most cases, duplicate samples have been analyzed.

\$ The number of gene copies per haploid genome shown in parentheses was calculated as described previously (3) as follows: The fraction of a single globin gene in the human genome was calculated as $1.1 \times 10^{-7}(3)$. Thus, the above experiments were performed in "relative cDNA excess" with three times as much cDNA as for a single globin gene (3.3 $\left.\times 10^{-7} / 1.1 \times 10^{-7}=3\right)$. The number of globin genes $(N)$ was then calculated from the equation $1(N) /(1(N)+3)=\%$ hybridization. For example: for normal spleen-1: $N /(N+3)$ $=39 \%, N=2$. 
$\gamma$ cDNA was primarily nonglobin cDNA specifically present in cord blood cells, the nonglobin mRNA it represented would not be present in amounts comparable to that of $\alpha$ mRNA in the cells of an adult patient with $\delta \beta$-thalassemia. Similarly, it should not be present in large amounts in the cells of adult patients with $\beta$-thalassemia (Fig. 4, Table I). With these considerations, the $\gamma$ cDNA is approximately $80 \%$ purified $\gamma \mathrm{cDNA}$. The high $C_{o} t$ values required to fully hybridize the $\gamma$ cDNA to normal reticulocyte mRNA and hemoglobin $\mathrm{H}$ mRNA is additional evidence that the $\gamma$ cDNA is primarily $\gamma$ cDNA.

The lack of significant cross-hybridization of $\gamma$ cDNA with $\beta$ mRNA sequences under the conditions used is quite remarkable, since the amino acid sequence of $\gamma$ and $\beta$ chains differ by only 38 of 146 amino acids (18). Thus, it appears that there are more mutations in the nucleotide sequence coding for these globin genes than are reflected by changes in the amino acid sequence of $\gamma$ - and $\beta$-globin. The nucleotide changes are apparently numerous enough to prevent stable hybrids between $\gamma$ and $\beta$ nucleotide sequences. It is possible that $\gamma$ cDNA sequences homologous to $\alpha$ and $\beta$ mRNA exist but have been removed by our method of preparing $\gamma \mathrm{cDNA}$. However, the specificity of the $\gamma$ cDNA isolated suggests that such sequences do not exist in the cDNA we have obtained, which contains about 500 nucleotides. The results also indicate that the amount of $\gamma$ mRNA present in globin mRNA from human cells is roughly proportional to the relative amount of $\gamma$-globin translated in both intact cells and by mRNA in cell-free systems (Table I).

With purified $\alpha$ - and $\beta$-globin cDNA, it has been possible to quantitate the relative numbers of $\alpha$ - and $\beta$-globin genes in normal and $\beta$-thalassemia cellular DNA. With these probes, it has been possible to demonstrate specific deletions of either $\alpha$ - or $\beta$-like globin gene material in $\alpha$ - and $\delta \beta$-thalassemia $(4,6-8)$ and in hereditary persistence of fetal hemoglobin (8-10). Similar results have been obtained with measurements of $C_{o} t$ kinetics in cellular DNA excess $(6,7,9,10)$ and by limited cDNA excess hybridization $(4,8)$. We prefer this latter method, which relies on the saturation plateaus obtained, since it requires less cellular DNA and is quite reproducible $(3,4,8$; Table II).

In this paper, we have used the $\gamma$ cDNA probe to compare the amount of $\gamma$-globin DNA in thalassemia and nonthalassemia DNA. The number of $\gamma$-globin genes in cellular DNA from patients with $\beta$-thalassemia is similar to those in nonthalassemia DNA (Table II). Comparable numbers of $\alpha$ - and $\beta$-globin genes have been previously reported in $\beta^{+}$-thalassemia DNA as in nonthalassemia DNA $(3,4)$. In the studies reported here, both $\beta^{+}$- and $\beta^{0}$-thalassemia DNA were used and shown to contain $\gamma$-globin genes in amounts compar- able to normal DNA. These results indicate that there is no detectable deletion of structural $\gamma$-globin genes in the DNA of these patients. On the basis of its size, the $\gamma$ cDNA represents about 500 nucleotides homologous to the $\gamma$ mRNA and starting at the $3^{\prime}$ end of the RNA. Since there are approximately 100 adenylate residues at the $3^{\prime}$ end of globin mRNAs, the $\gamma$-globin cDNA contains about 400 nucleotides excluding the polyadenylate regions. Approximately 450 nucleotides are required to encode structural $\gamma$-globin; in addition, by analogy with $\alpha$ and $\beta$ mRNA, there are an additional 100 untranslated nucleotides at the $3^{\prime}$ end of $\gamma$ cDNA. Thus, the $\gamma$ cDNA probably represents about $70 \%$ of the structural $\gamma$-globin gene sequence $(400 / 550)$. It is, therefore, possible that deletions in the $\gamma$-globin gene homologous to the $5^{\prime}$ end of the $\gamma$-globin mRNA will be undetected by this probe. With this reservation in mind, the results suggest that deletion of $\gamma$-globin genes cannot account for the decreased amount of $\gamma$-globin present in the cells of $\beta$-thalassemia patients. In addition, they indicate that a deletion of $\gamma$-globin genes is apparently unrelated to the decreased production of $\beta$-globin mRNA by $\beta$-globin genes in $\beta^{+}$-thalassemia.

It is difficult to compare the absolute number of $\alpha-, \beta$-, and $\gamma$-globin genes with the methodology in this paper, since the precise gene numbers depend on the absolute purity and length of the cDNA probes used, the absolute specific activity of these probes (which can only be calculated), the hybridization of the cDNA probes to nonglobin gene material or untranscribed globin gene material in cellular DNA, and variations in the relative hybridization of CDNA to DNA at varying cDNA to DNA inputs (3). For these reasons, it is difficult to compare the relative hybridization of cellular DNA to different cDNAs as a measure of the relative or absolute numbers of globin genes. It is more reliable to simply compare the hybridization of different cellular DNAs with the same probe at similar cellular DNA to cDNA inputs as reported here. Calculations of specific gene numbers can be made, within the limitations of this type of analysis. Comparing our present data to that we have published previously (4), we find that at similar levels of input of cDNA per cellular DNA, there is consistently less $\gamma$ cDNA hybridization obtained at saturation than with $\alpha$ and $\beta$ cDNA. Hybridization of $\alpha$ cDNA to human DNA may reflect not only the number of $\alpha$ genes but other embryonic $\alpha$-like genes as well. Similarly, hybridization of $\beta$ cDNA may well include $\delta$ gene hybridization as well as that of other embryonic $\beta$-like genes. Our previous data (4) and that of others (5) are consistent with strong genetic evidence for one $\beta$, one $\delta$, and two $\alpha$ loci per haploid human genome. The lack of cross-hybridization of $\gamma$ cDNA with $\beta$ or $\alpha$ nucleotide sequences demonstrated in this study makes 
it unlikely that hybridization of the $\gamma \mathrm{cDNA}$ is due to contamination with $\alpha$ or $\beta$ cDNA sequences or crosshybridization to $\alpha$ or $\beta$ genes. However, it is possible that the $\gamma$ cDNA hybridizes to embryonic or other $\gamma$-like genes that may be present in native human DNA. The $C_{o} t 1 / 2$ of the $\gamma$ cDNA hybridization is two- to threefold less than that of the total unique sequence DNA and indicate that $\gamma$-globin genes are present in very few copies. From the data obtained by saturation hybridization analysis, one to two $\gamma$ globin genes per haploid genome are calculated in these studies (Table II). All of the results are consistent with the two to four $\gamma$ globin genes per haploid genome, estimated from genetic data utilizing the relative amounts of $\gamma^{\text {Gly }}$ and $\gamma^{\text {ala }}$ in human subjects (19).

Since this work was completed, $\gamma$-globin gene measurements similar to ours have been reported with hybridization in a vast excess of cDNA (20). In this report (20), the authors state that there is less variability in gene numbers and greater sensitivity with a vast excess of cDNA. However, these same authors were unable to detect a deletion of $\beta$-like globin genes in a heterozygote for $\delta \beta$-thalassemia with excess cDNA hybridization (5), while we have been able to do so easily using the methodology described in this paper (8).

\section{ACKNOWLEDGMENTS}

These studies were supported in part by National Institutes of Health grants GM 14552, GM 19153, CA 03526, and CA 13696, National Heart and Lung Institute grant 5-P18HL1-15161, a National Science Foundation Research grant 27388, the National Foundation March of Dimes, grant 1-304, and the Cooley's Anemia Foundation.

\section{REFERENCES}

1. Packman, S., H. Aviv, J. Ross, and P. Leder. 1972. A comparison of globin genes in duck reticulocytes and liver cells. Biochem. Biophys. Res. Commun. 49: 813819.

2. Bishop, J. O., and M. Rosbach. 1973. Reiteration frequency of duck haemoglobin genes. Nat. New Biol. 241: 204-207.

3. Gambino, R., D. Kacian, J. V. O'Donnell, F. Ramirez P. A. Marks, and A. Bank. 1974. A limited number of globin genes in human DNA. Proc. Natl. Acad. Sci. U.S.A. 71: 3966-3970.

4. Ramirez, F., C. Natta, J. V. O'Donnell, V. Canale, G Bailey, T. Sanguensermsri, G. M. Maniatis, P. A. Marks, and A. Bank. 1975. Relative numbers of human globin genes assayed with purified $\alpha$ and $\beta$ complementary human DNA. Proc. Natl. Acad. Sci. U.S.A. 72: 1550-1554.

5. Ottolenghi, S., W. G. Lanyon, R. Williamson, D. J. Weatherall, J. B. Clegg, and C. S. Pritchard. 1975. Human globin gene analysis for a patient with $\beta^{0} / \delta \beta^{0}$ thalassemia. Proc. Natl. Acad. Sci. U.S.A. 72: 2294-2299.
6. Taylor, J. M., A. Dozy, Y. W. Kan, H. E. Varmus, L. E. Lie-Injo, J. Ganesan, and D. Todd. 1974. Genetic lesion in homozygous $\alpha$ thalassemia (hydrops fetalis). Nature (Lond.) 251: 392-393.

7. Ottolenghi, S., W. G. Lanyon, J. Paul, R. Williamson, D. J. Weatherall, J. B. Clegg, J. Pritchard, S. Pootrakul, and W. H. Boon. 1974. The severe form of $\alpha$ thalassemia is caused by haemoglobin gene deletion. Nature (Lond.) 251: 389-392.

8. Ramirez, F., J. V. O’Donnell, P. A. Marks, A. Bank, S. Musumeci, G. Schilirò, G. Pizzarelli, G. Russo, B. Luppis, and R. Gambino. 1976. Abnormal or absent $\beta$ mRNA in $\beta^{0}$ Ferrara and gene deletion in $\delta \beta$ thalassemia. Nature (Lond.) In press.

9. Kan, Y. W., J. P. Holland, A. M. Dozy, S. Charache, and H. H. Kazazian. 1975. Delection of the $\beta$-globin structure gene in hereditary persistance of fetal haemoglobin. Nature (Lond.) 258: 162-163.

10. Forget, B. G., D. G. Hillman, H. Lazarus, E. F. Barell, E. J. Benz, Jr., C. T. Caskey, T. H. J. Huisman, W. A. Schroeder, and D. Housman. 1976. Absence of messenger RNA and gene DNA for $\beta$-globin chains in hereditary persistance of fetal hemoglobin. Cell. 7: 323-329.

11. Dow, L. W., M. Terada, C. Natta, S. Metafora, E. Grossbard, P. A. Marks, and A. Bank. 1973. Globin synthesis of intact cells and activity of isolated mRNA in $\beta$-thalassemia. Nature (Lond.) 243: 114-116.

12. Lanyon, W. G., S. Ottolenghi, and R. Williamson. 1975. Human globin gene expression and linkage in bone marrow and fetal liver. Proc. Natl. Acad. Sci. U.S.A. 72: 258-262.

13. Kacian, D. L., S. Spiegelman, A. Bank, M. Terada, S. Metafora, L. Dow, and P. A. Marks. 1972. In vitro synthesis of DNA components of human genes for globins. Nature (Lond.). 235: 167-169.

14. Maniatis, T., A. Jeffrey, and H. van deSande. 1975. Chain length determinations of small double and single stranded DNA molecules by polyacrylamide gel electrophoresis. Biochemistry. 14: 3787-3794.

15. Kacian, D. L., R. Gambino, L. W. Dow, E. Grossbard, C. Natta, F. Ramirez, S. Spiegelman, P. A. Marks, and A. Bank. 1973. Decreased globin messenger RNA in thalassemia detected by molecular hybridization. Proc. Natl. Acad. Sci. U.S.A. 70: 1886-1890.

16. Ramirez, F., R. Gambino, G. M. Maniatis, R. A. Rifkind, P. A. Marks, and A. Bank. 1975. Changes in globin mRNA content during erythroid cell differentiation. J. Biol. Chem. 250: 6054-6058.

17. Russo, G., S. Musumeci, G. Schilirò, A. D'Agata, and G. Pizzarelli. 1974. Sintesi "in vitro" delle catene polipeptidiche della globina nelle talassemie ed in alcune emoglobinopatie. Atti Soc. Ital. Ematol. 1: 197-205.

18. Weatherall, D. J., and J. B. Clegg. 1973. The Thalassemia Syndromes. 2nd Edition, Blackwell, Oxford, England. $374 \mathrm{pp}$

19. Schroeder, W. A., T. H. J. Huisman, J. R. Shelton, J. B. Shelton, E. F. Kleihauer, A. M. Dozy, and B. Robberson. 1968. Evidence for multiple structural genes for the $\gamma$ chain of human fetal hemoglobin. Proc. Natl. Acad. Sci. U.S.A. 60: 537-544.

20. Old, J., J. B. Clegg, D. J. Weatherall, S. Ottolenghi, P. Comi, B. Giglioni, J. Mitchell, P. Tolstoshev, and R. Williamson. 1976. A direct estimate of the number of human $\gamma$ globin genes. Cell. 8: 13-18. 